an excellent journal and in my eyes the limited and strictly controlled advertising/product news adds to the interest of the title rather than detracts from it.

C. Baker

Chippenham

DOI: 10.1038/sj.bdj.2013.115

\section{AN ACT OF FAITH}

Sir, I was pleased to read the timely editorial on the nature of verifiable CPD. ${ }^{1}$ I share your views concerning the issues raised in what might be simplistically thought of as the task of 'getting the answers right'. They are, as you rightly acknowledge, far from easy to resolve.

For over 30 years as a part-time clinical teacher I have been involved with courses of differing levels serving many types of participant. I often ask myself what does everyone get from the experience and is there any way it can be reliably measured? The use of stated course objectives, questionnaires, interviews, quizzes, focus groups and the like are some of the standard tools used in order to demonstrate that the process is 'fit for purpose'. All are potentially helpful but none in my view can truly gauge the effect of any particular course content, teaching or instruction and indeed how it will influence the performance of any particular individual now or in the future. This is very inconvenient.

I do, however, share my colleague Martin Kelleher's concerns about a system which fails to encourage and reward those who diligently seek to improve and apply their skills and knowledge, acquired through genuine application and study. ${ }^{2}$ This unpleasant realism does somewhat undermine the credibility of the ethos of continuing professional development as seen here in the United Kingdom.

I do not have any ready panaceas to contribute to the debate save the observation that the process can be likened to an act of faith 'the substance of things hoped for; the evidence of things not yet seen'.

B. R. Davies, by email

1. Hancocks S. One on one. Br Dent J 2012; 213: 487

2. Kelleher M. The difficulties of making 'CPD verifiability' a legitimate measure of learning outcomes. Br Dent J 2012; 213: 383-384.

3. Hebrews 11:1.

DOI: 10.1038/sj.bdj.2013.116

\section{EFFICACIOUS E-304}

Sir, I refer to the news item 'Food preservatives could aid cancer fight' in the 7 December 2012 issue of the $B D J$ (213: 543) and would like to add some comments.

Our charity has been working for some years using E-304 (aka palmitoyl ascorbate or ascorbyl palmitate [USA]) which has been found to be efficacious in extending life in cases of colon cancer deemed inoperable or with a prognosis of three months or less to live. E-304 is widely used in the food industry and has an LD50 of $3000 \mathrm{mg} / \mathrm{kg}$ (worst case in guinea pig) so it is inherently safe. At an oral intake of $1 \mathrm{~g}$ /day stirred into yoghurt it has proved to be easy to take and effective. In vitro it is a powerful anti-angiogenic. It is also lipid soluble and therefore likely to penetrate the host/tumour interface. Here the product of its interaction with homocysteine lactone produced by tumour cells into the area of contact with host tissue would provide an opportunity for formation of the toxic 3-mercaptopropionaldehyde around and within the cell membrane and subsequent apoptosis of the tumour cell.

These two properties alone are sufficient to suggest it is of prime interest in cancer control. E-304 has also been used for some years as a means of keeping low Ca125 counts in recovering ovarian cancer cases where hormonal treatment has been of limited value.

\section{A. Carmichael}

Parkinson's Improvement Programme

1. Poydock M E, Reikert D, Rice J, Aleandri L. Inhibiting effect of dehydroascorbic acid on cel division in ascites tumors in mice. Exp Cell Biol 1982; 50: 34-38.

2. Poydock M E, Reikert D, Rice J. Influence of vitamins $C$ and $B 12$ on the survival rate of mice bearing ascites tumor. Exp Cell Biol 1982; 50: 88-91.

3. Jabukowski H, Goldman E. Synthesis of homocysteine thiolactone by methionyl-tRNA synthetase in cultured mammalian cells. FEBS Lett 1993; 317: 593-598.

4. Jabukowski H. Metabolism of homocysteine thiolactone in human cell cultures. Possible mechanism for pathological consequences of elevated homocysteine levels. J Biol Chem 1997; 272: 1835-1942

5. Toohey J I. Dehydroascorbic acid as an anti-cancer agent. Cancer Lett 2008; 263: 164-169.

DOI: 10.1038/sj.bdj.2013.117

\section{STICKY SALIVA PRODUCTS}

Sir, in their excellent update on Sjögren's syndrome (BDJ 2012; 213:

353-357) A. J. Carr and co-authors indicate that artificial saliva products may have limitations in effectiveness. This suggestion is supported by a recent study we performed at the national meeting of the Dutch Sjögren's Patients Federation. This meeting took place on 6 October 2012, and was attended by approximately 350 patients with Sjögren's disease. Seventy-two patients approached randomly were interviewed about their current and past use of artificial saliva products.

Sixty percent of the interviewed patients with Sjögren's disease reported that they ever had used an artificial saliva spray, $67 \%$ had ever used a gelbased oral lubricant and 25\% a special mouthrinse. However, more than half of the patients had discontinued the use of these products. Currently, only 21\% of the patients were still using an artificial saliva spray, $28 \%$ a gel-based lubricant and $14 \%$ a special mouthrinse.

The major reasons for discontinuation of artificial saliva products were lack of effectiveness and taste. Another frequently reported reason for discontinuation of gel-based oral lubricants was that patients considered it too 'sticky'. The availability of artificial saliva products in stores and the price of the product were only rarely mentioned as reason to discontinue its use.

We conclude that many patients with Sjögren's disease consider the effectiveness and taste of the currently available artificial saliva products as inadequate. There seems to be a need for novel, effective products that provide long lasting relieve, are easy to administer and non-sticky, and have a pleasant taste. For the development of effective artificial saliva products, it might be wise to consult patients with Sjögren's disease about product characteristics at an early stage of the development process.

\section{H. S. Brand, R. Ouzzine, C.P. Bots Amsterdam DOI: 10.1038/sj.bdj.2013.118}

The $B D J$ website now includes a facility enabling readers to immediately comment on letters. All comments must comply with the nature.com Terms and Conditions and Community Guidelines visit the $B D J$ website to find out more and to post your comment now. 